\title{
A species-centered approach for uncovering generalities in organism responses to habitat loss and fragmentation
}

\author{
Matthew G. Betts, Lenore Fahrig, Adam S. Hadley, Katherine E. Halstead, Jeff Bowman, \\ W. Douglas Robinson, John A. Wiens and David B. Lindenmayer
}

M. G. Betts (matthew.betts@oregonstate.edu), Dept of Forest Ecosystems and Society, Oregon State Univ., Corvallis, OR 97331, USA. - L. Fahrig, Ottawa-Carleton Inst. of Biology, Carleton Univ., Ottawa, ON KIS 5B6, Canada. - A. S. Hadley, Dept of Forest Ecosystems and Society, Oregon State Univ., Corvallis, OR 97331, USA. - K. E. Halstead, Forest Ecosystems and Society, Oregon State Univ., Corvallis, OR 97331 , USA. - J. Bowman, Wildlife Research and Monitoring Section, Ontario Ministry of Natural Resources, 2140 East Bank Drive, Peterborough, ON K9J 7B8, Canada. - W. D. Robinson, Oak Creek Lab of Biology, Dept of Fisheries and Wildlife, Oregon State Univ., Corvallis, OR 97331, USA. - J. A. Wiens, Point Blue Conservation Science, Petaluma, CA 94954, USA, and School of Plant Biology, Univ. of Western Australia, Crawley, WA 6009, Australia. - D. B. Lindenmayer, Fenner School of Environment and Society, ARC Centre of Excellence for Environmental Decisions and National Environment Research Program, The Australian National Univ., Canberra, ACT 0200, Australia.

\begin{abstract}
Theoretical models predict strong influences of habitat loss and fragmentation on species distributions and demography, but empirical studies have shown relatively inconsistent support across species and systems. We argue that species' responses to landscape-scale habitat loss and fragmentation are likely to appear less idiosyncratic if it is recognized that species perceive the same landscapes in different ways. We present a new quantitative approach that uses species distribution models (SDMs) to measure landscapes (e.g. patch size, isolation, matrix amount) from the perspective of individual species. First, we briefly summarize the few efforts to date demonstrating that once differences in habitat distributions are controlled, consistencies in species' responses to landscape structure emerge. Second, we present a detailed example providing step-by-step methods for application of a species-centered approach using freely available land-cover data and recent statistical modeling approaches. Third, we discuss pitfalls in current applications of the approach and recommend avenues for future developments. We conclude that the species-centered approach offers considerable promise as a means to test whether sensitivity to habitat loss and fragmentation is mediated by phylogenetic, ecological, and life-history traits. Cross-species generalities in responses to habitat loss and fragmentation will be challenging to uncover unless landscape mosaics are defined using models that reflect differing species-specific distributions, functional connectivity, and domains of scale. The emergence of such generalities would not only enhance scientific understanding of biotic processes driving fragmentation effects, but would allow managers to estimate species sensitivities in new regions.
\end{abstract}

Habitat destruction is considered to be one of the primary threats to biodiversity worldwide (Balmford et al. 2003) and has become a dominant topic for research in conservation biology (Ewers et al. 2010). Given that $50-70 \%$ of the earth's surface is now exploited for human use (Barnosky et al. 2012), the focus of policy and research on this topic is likely to intensify. This substantial body of knowledge reveals remarkable diversity in the responses of species and ecological processes to landscape-scale habitat loss and fragmentation. For example, a global-scale metaanalysis examining the effects of patch size and isolation on animal populations found weak and highly variable effects of these variables (Prugh et al. 2008). In a meta-analysis of the influence of 'patch size' on population density, Connor et al. (2000) found that although the overall effect of patch size was positive, $40 \%$ of relationships reported were negative and $\sim 60 \%$ positive. Only $5 \%$ of variance in density across species was explained by patch size.
There is therefore a striking contrast between the rather idiosyncratic results of empirical work and those of models traditionally used to predict effects of habitat loss and fragmentation - island biogeography theory (IBT) and metapopulation dynamics - which predict strong and consistent influences of both habitat loss and fragmentation on biodiversity (MacArthur and Wilson 1967, Hanski 1998). It has frequently been argued that, in most cases, real landscapes are too complex to reflect the rather simplistic reality of these models (McIntyre and Barrett 1992, Didham et al. 2012). However, there is also the alternative hypothesis that methods for conceptualizing and quantifying fragmentation and habitat loss may previously have lacked the accuracy and precision to detect more general effects.

Here, we suggest that it is not yet possible to reject this second hypothesis. Since the early days of landscape ecology, it has been recognized that the distribution of 
habitat patches is likely to vary strongly among species because habitat is, by definition, a species-specific concept (Wiens 1976, Haila 2002). Different species perceive a 'landscape' in different ways, depending on their lifehistory requirements, associations with major vegetation types, and prey distributions (Fischer et al. 2005). However, the general recognition of these realities has only rarely been reflected in empirical studies; most studies continue to quantify landscapes using human-defined cover types, which may have little relation to how individual species perceive habitat distributions across landscapes. We argue that this mismatch between how species see landscapes and how we measure them may be a root cause of the apparent idiosyncratic responses among species to the effects of landscape-scale habitat loss and fragmentation. We review previous efforts that have attempted to incorporate a 'species-eye' view of the landscape, and provide a worked example of how to use species distribution models (SDMs) to begin to reflect landscape patterns from species' perspectives.

It is important to distinguish three aspects of landscape change influencing species distributions and demography. The clearest impact of landscape change on species occurs when habitat is lost at the local scale (i.e. the scale of an individual animal territory). By definition, if habitat is destroyed at this scale, the species cannot occur, so habitat loss results in a proportionate decline in the number of animals living in a particular landscape (Haila et al. 1983). Unsurprisingly, this effect tends to be consistent across studies. In contrast, the impact of changes in habitat amount at landscape scales (i.e. beyond the scale of the individual territory or home range), and habitat fragmentation (i.e. the spatial pattern of remaining habitat) vary considerably across species for reasons that remain cryptic. It is the study of these two final types of habitat change which we suggest could benefit from a species-centered approach.

\section{The species-centered approach}

The 'continua-Umwelt' (Manning et al. 2004) and the continuum models (Fischer and Lindenmayer 2007) advanced beyond IBT in that they: 1) embrace, rather than ignore, spatial gradients in habitat suitability and landscape resistance to movement; and 2) recognize that each species may respond to landscape elements in different ways. These conceptual models of landscape fragmentation have strong parallels in the concept of 'functional connectivity' - the degree to which the landscape facilitates or impedes movement among resource patches (Taylor et al. 1993), which is also a species-specific construct (Tischendorf and Fahrig 2000, Belisle 2005). For instance, movement of forest generalists (e.g. species found in both intact and degraded forests) are less likely to be impeded by a contrasting matrix than those of forest specialists (e.g. species mainly restricted to intact forests; Gillies and Clair 2008, Smith et al. 2011). Similarly, the concept of 'functional landscape heterogeneity' asserts that the definition and mapping of cover types on a landscape should be based on the expected functions they serve (e.g. provision of food, nesting sites, dispersal routes) to the species of interest; thus, the description of a landscape is species-specific (Fahrig et al. 2011).

The formal recognition of a 'species-eye' view of the landscape - in terms of species distributions and movement has important implications when it comes to searching for generality in species responses to landscape structure. If the sorts of patches that humans recognize and map (e.g. 'mature forest', 'native grassland') are actually super-sets of, or simply spatially incongruent with, the patches actually perceived by plants and animals, it is quite likely that our quantification of landscape metrics contain substantial errors (Fig. 1). By defining patches as general, human-derived cover types, we may be accurately depicting 'true' patchiness for only a small
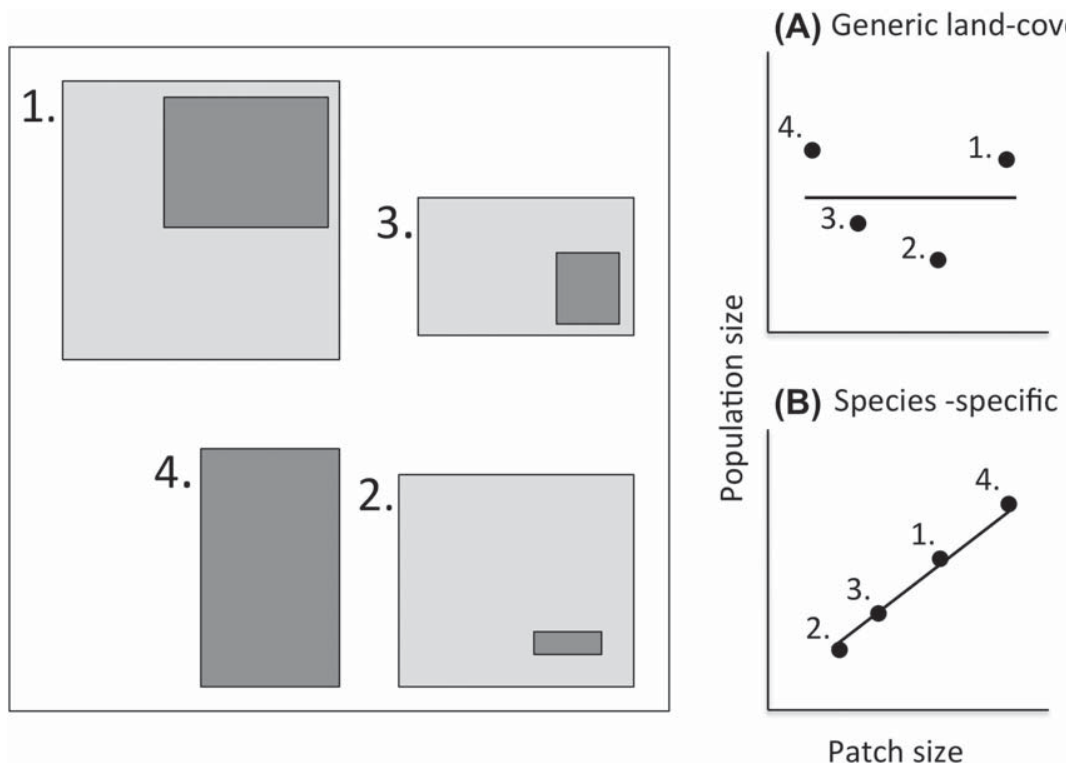

Figure 1. Conceptual representation of a landscape containing patches of a generic land-cover type (e.g. tropical forest) within which a hypothetical species is sufficiently specialized to use only subsets of these patches. Note that in this case, tropical forest patch size (light gray) is not correlated with species-specific patch size (dark gray). Under such conditions, even if boundaries between tropical forest and matrix are unambiguous, no influence of patch size will be detected (A), even if population size is strongly related to speciesspecific patch size (B). Such instances could lead policy makers to conclude that there is no effect of patch size when in fact there is. 
subset of species. If the amount and configuration of habitat in most studies is generally quantified using human-based definitions, such as 'discrete terrestrial habitat patches of the same general habitat type' (Prugh et al. 2008), it is perhaps not surprising that only minor effects of patch size and isolation have been reported across studies and generality has been elusive. Indeed, the best-known examples in which population dynamics are clearly driven by the spatial structure of remaining habitat are from species that occupy clearly distinguishable patches in an unambiguous matrix (e.g. butterflies in meadow patches containing known food plants in a high-contrast matrix; Hanski 2011).

Interestingly, the importance of adopting a specieseye view of the landscape has received indirect support from several major efforts to identify life-history traits associated with habitat loss and fragmentation. Using the Breeding Bird Atlas for France, Devictor et al. (2008) found that habitat generalists (those using many coarsely defined cover types) were far less sensitive to habitat loss and fragmentation than habitat specialists. This could be interpreted as indicating that habitat generalists are not actually losing habitat when disturbance occurs; for such species, disturbed landscapes are likely to be more contiguous. In further support, Prugh et al. (2008) found that the sensitivity of amphibians, mammals, and birds to patch size was greater in instances where the intervening land (the 'matrix') was disturbed by humans than by natural processes. They partially attributed the difficulty of defining and delineating habitat patches in terrestrial landscapes to the possibility that animals may in fact use apparent 'non-habitat' matrix for breeding and movement much more frequently than identified a priori by researchers. Even adopting coarse definitions of matrix appears to increase the reported effects of fragmentation per se (Watling et al. 2011). In a similar vein, the response of species to 'edges' has appeared highly idiosyncratic across studies and species. However, when considered in the context of particular resources used by individual species (e.g. food availability), Ries et al. (2004) were able to successfully predict positive, neutral, or negative responses by individual species to edges.

While continuum models are conceptually appealing, research that explicitly incorporates a species-eye view of landscapes and assesses habitat loss and fragmentation effects is still rare. This is most likely because there have been substantial difficulties in operationalizing this approach (Haila 2002); quantifying the way 'habitat' is distributed across entire landscapes for multiple species has been held back by a lack of appropriate tools and data (Lindenmayer et al. 1995).

Fortunately, the availability of remotely sensed data (Guisan and Zimmermann 2000), combined with recent powerful models for quantifying species distributions (Elith et al. 2006), makes quantifying landscape structure from a species-eye view much more accessible. It is now possible to develop species distribution models (SDMs) using freely available, fine-resolution remote sensing data (e.g. Landsat TM) (Box 1; Shirley et al. 2013). It is becoming increasingly common to map species distributions as a function of land cover and climatic regimes ( $\mathrm{Lu}$ et al. 2012). Such efforts have made it strikingly clear that habitat distributions within the same landscape vary widely among species. The next step, then, is to test how the spatial patterns of such habitats (i.e. amount and fragmentation) in turn influence species distributions and demography.

As an example, Betts et al. (2007) tested the fragmentation threshold hypothesis (sensu Andrén 1994) using an approach that relied on SDMs to generate a priori spatial distribution of habitat for multiple bird species in a forest mosaic. Habitat amount and distribution were quantified separately for each species, and in many cases there was little overlap. Using this approach, they found some consistency in thresholds in landscape-scale habitat loss across species; for six of nine species examined, species occupancy dropped precipitously when habitat amount at the landscape scale declined below 5-30\%. This was in contrast to the lack of consistent effects of generic, human-defined variables on these same species found in a previous study (Betts et al. 2006).

The species-centered approach also has been used to estimate the effects of habitat loss on vital rates. Zitske et al. (2011) tested the degree to which habitat loss - measured as both generic mature forest and using SDMs - influenced the apparent survival of two warbler species. The SDM approach indicated strong effects of habitat loss on survival for both species in a consistent fashion, whereas models using human-defined 'mature forest' were unsupported. Using generic measures of landscape structure would have led researchers to conclude that mature forest loss had no effect on survival of either species. Using a species-centered approach, which accounted for the fact that one species was an extreme habitat generalist, allowed consistencies to emerge in the way both species' survival responded to habitat loss.

\section{The species centered approach: a worked example}

We present a detailed example of how a species-centered approach can be used to test for consistent patterns in habitat loss and fragmentation research. This approach requires three major steps: 1) quantify the distribution of 'habitat' for each species at the local scale using SDMs (Fig. 2C), 2) summarize habitat distributions into landscapescale metrics (e.g. in this case landscape-scale habitat amount; Fig. 2D-F), 3) test the degree to which landscapescale predictors further influence species occurrence, independent of local scale influences (Fig. 3D, 4). Note that this approach explicitly tests the degree to which landscapescale metrics can explain absences from what might appear to be appropriate local-scale habitat. Local-scale variables reflect aspects of forest stand structure and composition (sensu MacArthur and MacArthur 1961). Landscape metrics reflect ecological processes such as reduced site colonization due to dispersal limitation or mass effects (Leibold et al. 2004).

To do this, we collected data on bird distributions from 2002-2005 at 790 individual spatial locations in the southern Rogue River Basin of Oregon using avian point counts (Ralph et al. 1995). The Rogue River Basin is dominated by various types of oak forest (Table 2) embedded in a matrix of native grassland $(5 \%)$, farmland $(\sim 6 \%)$ 


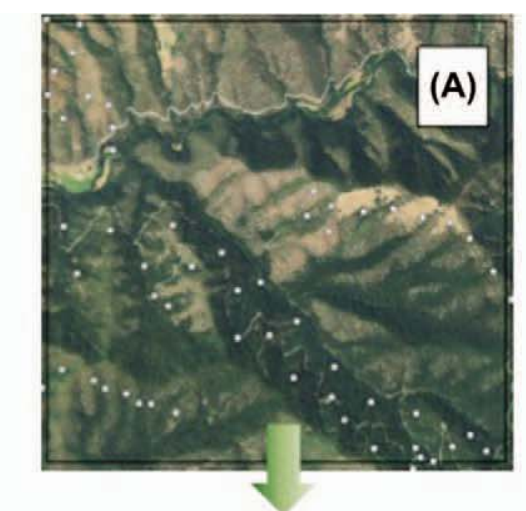

Point count data from a $4 \times 4 \mathrm{~km}$

landscape in the southern Rogue

Valley, Oregon

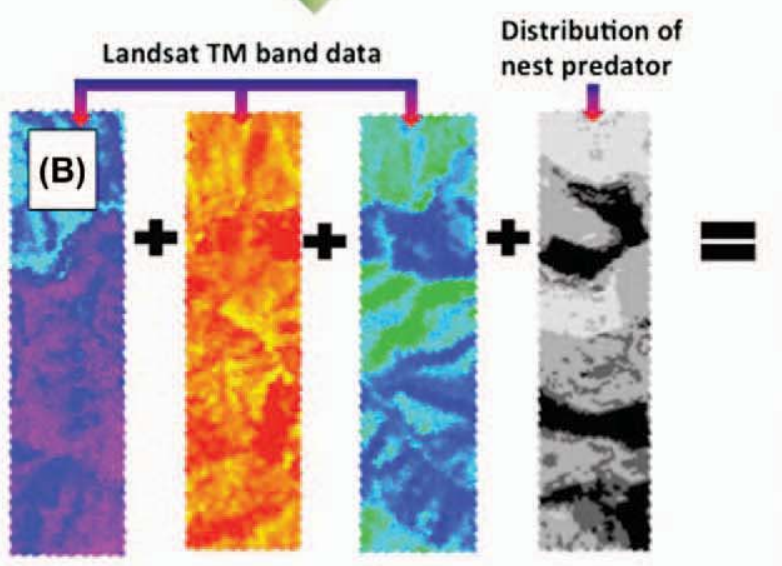

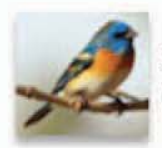

Species distribution model (SDM) for lazuli bunting

1 (high)

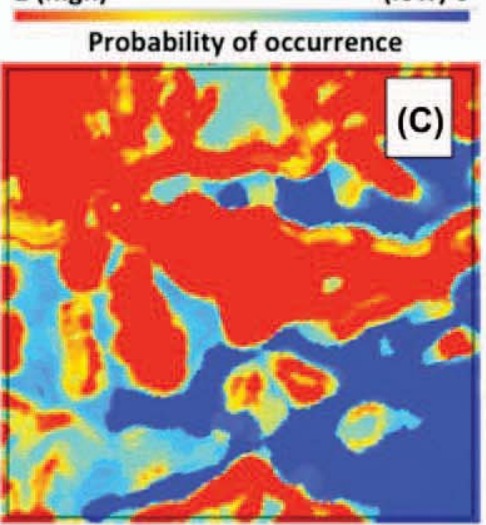

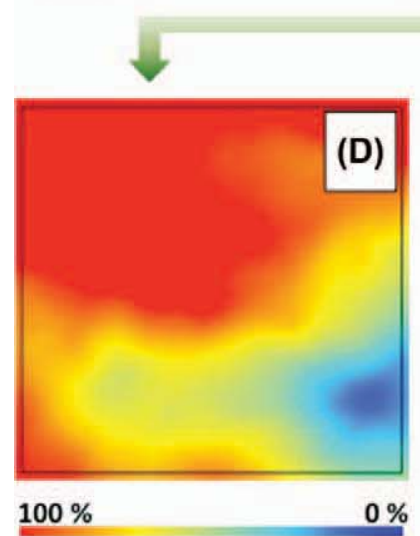

Percent habitat within $2000 \mathrm{~m}$

Amount of lazuli bunting

habitat summarized at a 2000

meter radius around every

pixel in the landscape (moving

window or neighborhood

analysis)

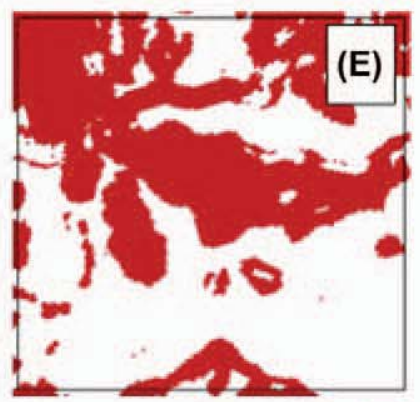

Habitat

Matrix

Patches of lazuli bunting habitat and matrix using a probability of occurrence cut-point of 0.5

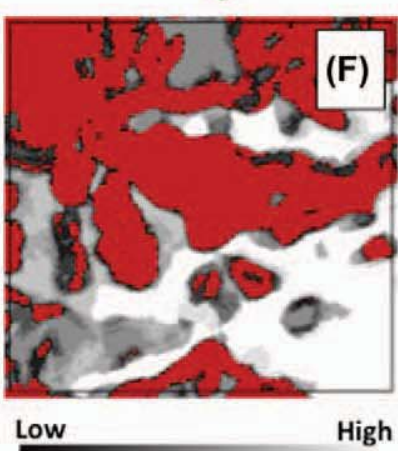

Degree of matrix resistance

Patches of habitat (red), with varying levels of matrix resistance

Figure 2. Using species distribution models (SDMs) to test for the effects of habitat loss and fragmentation at the landscape scale. (A) Data on species distributions and demography are often collected in landscapes that exhibit considerable ambiguity in habitat delineation. (B) Remotely-sensed data such as classified or unclassified Landsat TM data can be used in SDMs, potentially along with biotic factors (e.g. the presence of predators or competitors) to predict species distributions and generate spatial predictions for what constitutes 'habitat' for a given species (C). The resulting species-specific landscape structure can then be quantified using metrics such as the amount of habitat surrounding a pixel at biologically relevant scales (D), as well as mean patch size and edge density (E). In landscapes that are less dichotomous, variability in matrix quality can also be modeled using SDMs (F). 


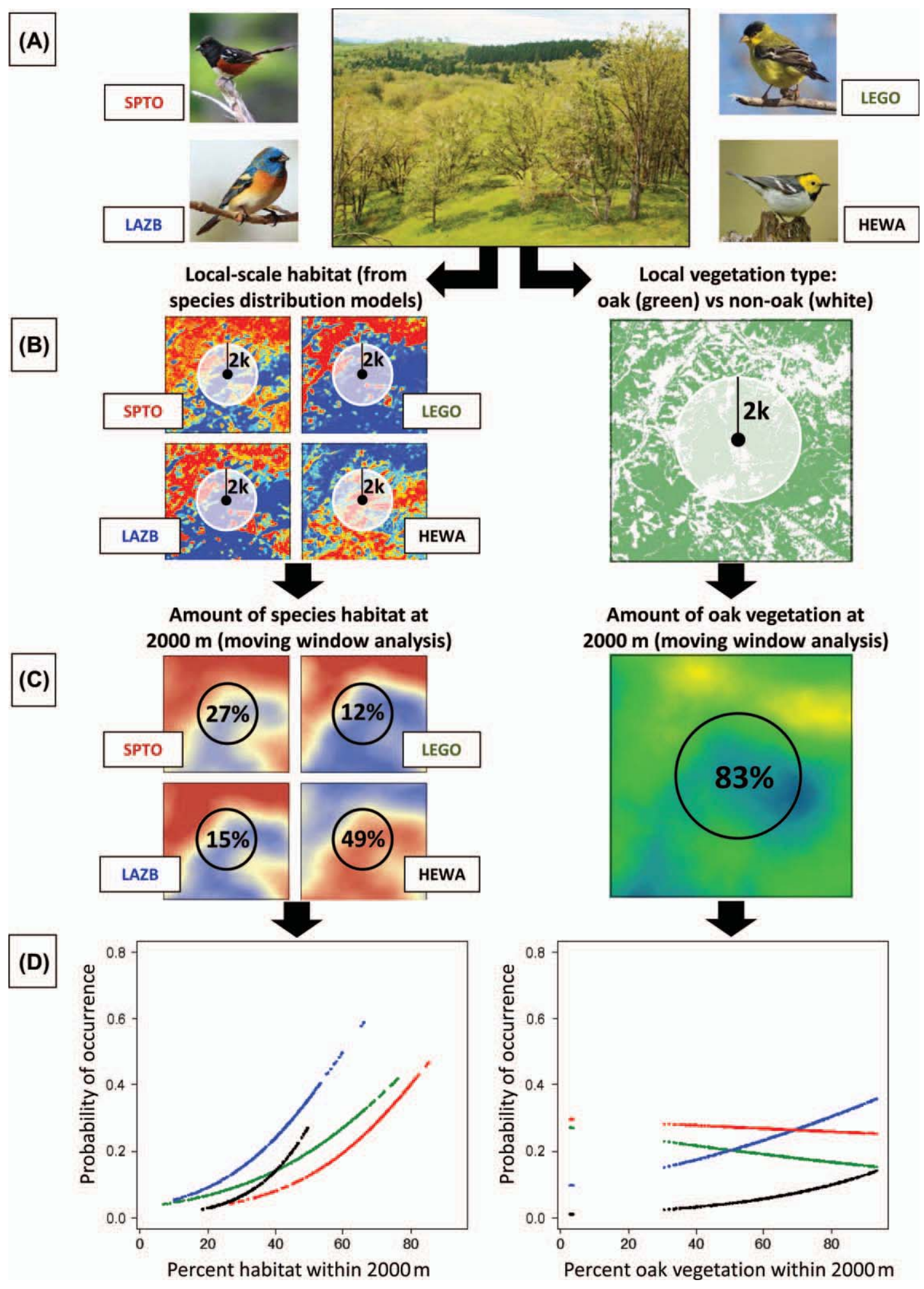

Figure 3. Application of 1) the species-centered approach and 2) a more typical use of generic land-cover types (in this case oak vegetation), in the oak savanna of the Rogue Valley, Oregon (A). Species distribution models were used to individually quantify habitat distributions at the local scale (30 m pixel) from the perspectives of four common bird species: spotted towhee (SPTO), lesser goldfinch (LEGO), lazuli bunting (LAZB) and hermit warbler (HEWA) (B). We then summarized the amount of habitat at landscape scales (2000 m radius) using a moving window analysis. Habitat amount across sample points varied considerably for each species ranging from 11\% (LEGO) to $49 \%$ (HEWA) in this example landscape (C). The probability of site occupancy varies strongly and consistently as a function of landscape structure quantified using a species-centered approach, but is highly inconsistent and weak when modeling it in response to vegetation type perceived by humans (oak) (D). 

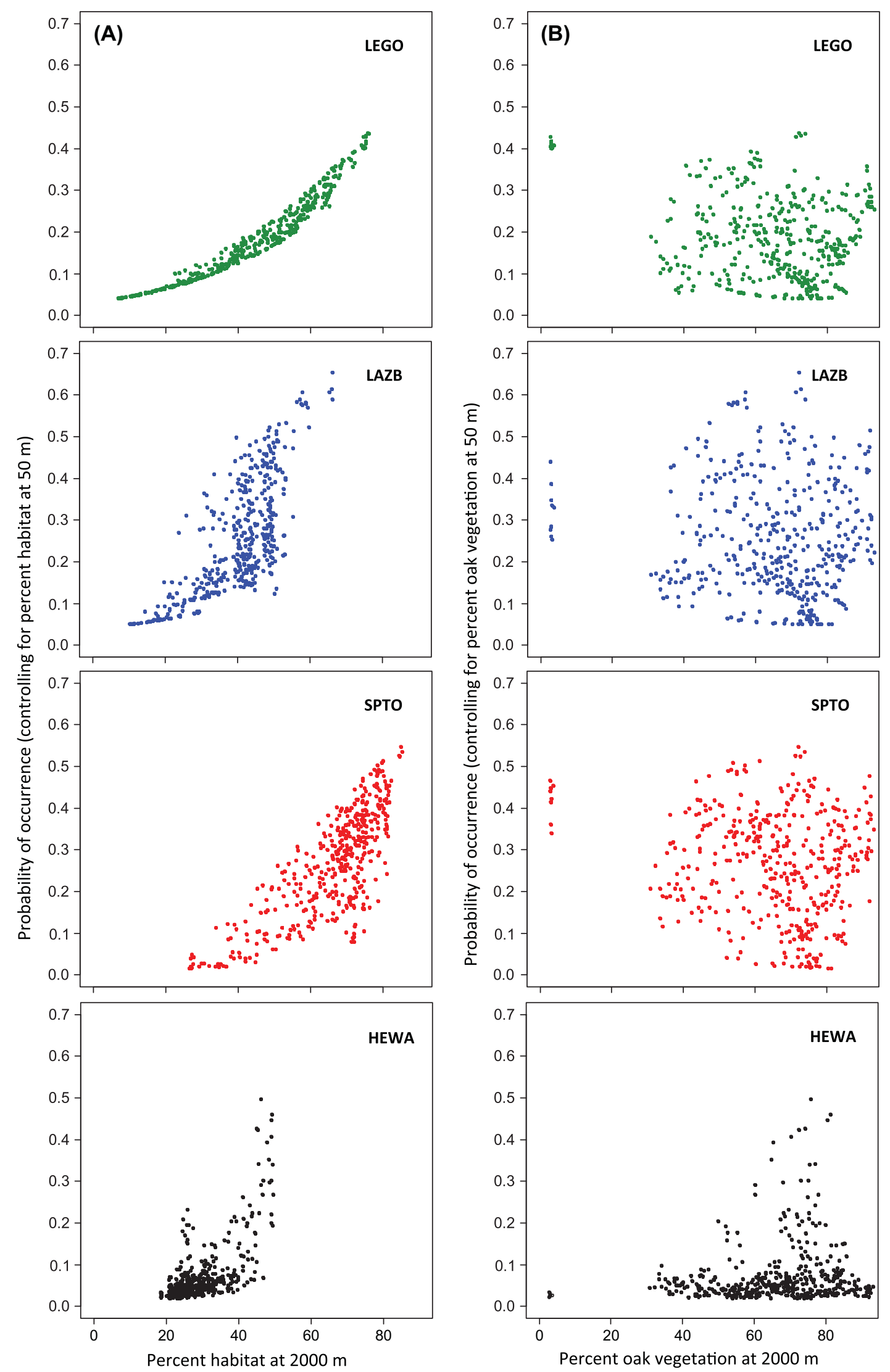

Figure 4. Results of a multiple logistic regression model where we tested for the effects of habitat amount using a species centered approach (A) and oak forest at landscape scales (B), after controlling for the effects of each of these variables a the local scale (50 m radius). Species codes are: lesser goldfinch (LEGO), lazuli bunting (LAZB), spotted towhee (SPTO) and hermit warbler (HEWA). 
and urban or recently disturbed area $(\sim 10 \%)$. Sample points were separated by $150-250 \mathrm{~m}$ and were originally established to study bird abundance along gradients of elevation, forest cover type, and disturbance (Shirley et al. 2013). Data were constrained to all auditory and visual detections occurring over a 5-min visit within $50 \mathrm{~m}$ of each point count location. For this example, we extracted data on presence/absence of three common forest-associated species in the dataset: spotted towhee Pipilo maculatus, lesser goldfinch Spinus psaltria, and lazuli bunting Passerina amoena that we expected to be strongly associated with oak savannah and woodland forest types. Each is listed as 'highly associated' with oak forest in the Rogue River Basin (Altman and Stephens 2012). For comparison we selected one species, hermit warbler Setophaga occidentalis, that we expected to be associated with conifer forest in the northwestern USA (Pearson 1997).

Land-cover data for the Rogue River Basin were comprised of six unclassified Landsat TM satellite imagery bands. All the Landsat images were acquired from USGS (<http://landsat7.usgs.gov/index.php $>$ ). Images from USGS had sub-pixel geolocation accuracies, and no further geometric processing was applied. We summarized Landsat bands at the $50-\mathrm{m}$ spatial extent, to reflect the scale at which small passerines exhibit territoriality (Bowman $2003)$ and the spatial scale of our avian census (50-m radius point counts).

We then used boosted regression trees (BRT; Elith et al. 2008) to model species distributions as a function of landcover data (after Shirley et al. 2013). Unlike traditional regression-based models that fit a single model using a response variable and a set of predictors, BRT models start with a simple classification or regression tree and use a boosting algorithm to iteratively fit new trees to the model in a forward, stage-wise fashion. One advantage of BRTs is their capacity to model non-linear relationships and interactions among predictor variables. Other regression models may be used to generate initial SDMs (e.g. logistic regression; Betts et al. 2007); however, for brevity we only report the results of BRTs here. Models for all four species performed well in 10-fold cross validation according to area under the receiver operating curve (AUC: lesser goldfinch $=0.81$, spotted towhee $=0.84$, hermit warbler $=0.82$, lazuli bunting $=0.83$ ), model sensitivity and specificity (Supplementary material Appendix 1, Table A1), and calibration plots (Supplementary material Appendix 1, Fig. A1). Ten-fold cross-validation iteratively used 90\% of the data to predict a randomly held-out $10 \%$ of the data. Although these model test sets were not spatially independent, it is important to note that the objective is only to accurately predict local-scale habitat distributions within our study area - rather to extrapolate to a new region.

We used the fitted probability of occurrence values of these local-scale models $(\hat{p})$ to map the spatial distribution of 'habitat' for each species (Fig. 3). We then applied a 'moving window' analysis to sum these habitat distributions at a scale we expected to be relevant to dispersal and movement of these species $(2-\mathrm{km}$ radius; Drapeau et al. 2000). In this way we estimated the total amount of habitat for each species at a biologically relevant scale surrounding each point in a landscape. We did not identify patches of habitat because this predominantly forested system is characterized more by gradients than by discrete patch boundaries, and in this simplified example, we wanted to present what is broadly considered the most important metric - landscapescale habitat amount (Fahrig 2003, 2013). However, previous studies have accomplished this by using statistical cut-points (e.g. the value of $\hat{p}$ that minimizes false positives and negatives) to distinguish habitat patches from nonhabitat (Betts et al. 2006; see Supplementary material Appendix 1, Table A1 for examples of such cut points). Using a similar approach, it is also possible to quantify 'matrix amount'; previous work has established a threshold value in $\hat{p}$ below which a species is highly unlikely to occur (Betts et al. 2006).

For comparison, we also calculated the total amount of oak forest surrounding each location in the landscape; this represents the sort of generic cover type that is frequently used as a predictor in landscape ecological studies. In southern Oregon, this forest type is of conservation concern (Seavy and Alexander 2011).

As a final step, we tested whether a) 'habitat amount' at the landscape scale, or b) oak forest could predict the distributions of each of the four species in a separate avian point count dataset that was collected at different spatial locations and in a different year (2010) from the data used to create the habitat distribution maps. These data were collected with identical methods within the same study region ( $\mathrm{n}=422$; Halstead 2013). These tests were conducted using logistic regression, with presence/absence of each species as the response variable and either habitat amount or oak forest as predictors. Note that although we were fortunate enough to have a second dataset to perform this test, this is not strictly necessary. Local-scale SDMs are generated in the first step of analysis. The subsequent, landscape-scale analysis addresses the question of whether additional variation in species occurrence can be explained by using summed habitat at landscape scales as a predictor.

The response by the four passerine bird species to habitat amount at landscape scales was similar and strongly statistically significant, whereas the response to amount of the dominant vegetation type, 'oak', was highly variable (Table 1, Fig. 3). To test whether this effect was driven primarily by local processes (i.e. local habitat amount) we conservatively statistically controlled for the effect of habitat amount at the $50-\mathrm{m}$ radius scale in a multiple logistic regression. Coefficients for habitat amount at the landscape scale (i.e. 2000-m radius) thus can be interpreted as being independent of local-scale habitat quality (Table 1: $\beta_{\text {independent }}$, Supplementary material Appendix 1). When we controlled for local habitat amount, results were more variable across species, but still substantially more consistent than considering generic 'oak forest' at the landscape scale.

These consistent results across species suggest that a consistent landscape-scale process (e.g. dispersal limitation, mass effects) is driving the distribution of these species. The species we considered represent a range of life-history traits (e.g. migrant/non-migrant, insectivores/seed eaters, groundnesters/canopy nesters) but a degree of generality emerged despite these differences.

It is important to emphasize that similar conclusions would be extremely difficult to obtain using finer-resolution 
Table 1. Parameter estimates $(\beta)$ from logistic regression models predicting the occurrence of four bird species as a function of both a) species-specific habitat amount at the $2 \mathrm{~km}$ spatial extent (i.e. the species-centered approach) and b) amount of oak forest at a $2 \mathrm{~km}$ spatial extent (a generic vegetation variable). Independent effects of habitat amount at $2 \mathrm{~km}$ scales $\left(\beta_{\text {independent }}\right)$ are results of a multiple regression model where we statistically controlled for habitat amount at the local scale (i.e. 50 m radius).

\begin{tabular}{lcc}
\hline Species & $\beta(\mathrm{SE})^{\S}$ & $\beta_{\text {independent }}(\mathrm{SE})$ \\
\hline $\begin{array}{l}\text { Species-specific habitat } \\
\text { amount within 2 km }\end{array}$ & & \\
Hermit warbler & $0.085(0.022)^{* * *}$ & $0.013(0.031)$ \\
Spotted towhee & $0.051(0.012)^{* * *}$ & $0.027(0.014)^{*}$ \\
Lazuli bunting & $0.058(0.013)^{* * *}$ & $0.025(0.015) \cdot$ \\
Lesser goldfinch & $0.041(0.009)^{* * *}$ & $0.036(0.010)^{* * *}$ \\
Oak forest within 2 km & & \\
Hermit warbler & $0.030(0.014)$ & $0.030(0.014)^{*}$ \\
Spotted towhee & $-0.002(0.006)$ & $0.0004(0.007)$ \\
Lazuli bunting & $0.018(0.006)^{*}$ & $0.014(0.007)$. \\
Lesser goldfinch & $-0.008(0.007)$ & $-0.011(0.008)$ \\
\hline *** & &
\end{tabular}

$\S * * * p<0.0001, * * p=0.0001-0.001, * p=0.01-0.05, \cdot p=0.05-0.01$.

vegetation cover type data, even if it were available. First, the habitat association of each species would need to show strong concordance with these finer-resolution types. We examined finer definitions of 'oak forest' in our study region (e.g. black oak conifer forest, white oak chaparral) and generally found a poor concordance between habitat distributions and these categories (Table 2). Second, finerresolution land-cover data still require a priori assumptions about what constitutes habitat. For most species, detailed information about cover-type usage does not exist. Importantly, if researchers used such qualitative a priori information to define 'habitat', if no effects of habitat amount or fragmentation effects were detected it would be inconclusive as to whether absence of effects was due to poor a priori definitions, or to true insensitivity of a species to landscape structure.

Based on this preliminary example from our study system, it seems that the approach of spatially defining habitat separately for each species shows promise for facilitating generalization across species in habitat loss and fragmentation research. However, for the species-centered approach to be tested more fully, similar methods must be applied across a broader range of taxa and ecological systems.

Table 2. Correlation coefficients $(r)$ for relationships between species-centered habitat distributions from SDMs and humandefined forest cover types in the Rogue River Basin, Oregon. Note generally poor concordance between human-defined categories and each species' habitat. Use of human-defined cover types to measure effects of habitat loss and fragmentation would require more finely defined vegetation categories and strong a priori understanding of how each is used as habitat by all species.

\begin{tabular}{lcccc}
\hline & $\begin{array}{c}\text { All } \\
\text { oak } \\
\text { vegetation }\end{array}$ & $\begin{array}{c}\text { White } \\
\text { oak } \\
\text { woodland }\end{array}$ & $\begin{array}{c}\text { White oak } \\
\text { and } \\
\text { chaparral }\end{array}$ & $\begin{array}{c}\text { Black oak } \\
\text { and } \\
\text { conifer forest }\end{array}$ \\
\hline Hermit warbler & 0.18 & -0.46 & -0.01 & 0.59 \\
Lazuli bunting & -0.04 & 0.44 & 0.21 & -0.48 \\
Lesser goldfinch & -0.17 & 0.55 & 0.06 & -0.68 \\
Spotted towhee & -0.13 & 0.42 & 0.07 & -0.52 \\
\hline
\end{tabular}

Given broad ranges in life-history traits - particularly those likely to influence landscape sensitivity (e.g. dispersal capacity, body size, longevity, reproductive output) - it is highly unlikely that all species will respond to landscape structure with similar trajectories, as seemed to occur in our example. However, the variations across taxa would be useful for generating hypotheses and testing the degree to which various life-history and ecological traits influence sensitivity to landscape structure (Vance et al. 2003, Holland et al. 2005).

\section{Limitations to the species-centered approach}

Although the species-centered approach appears to offer promise over traditional generic approaches to defining habitat pattern across landscapes, efforts to date have nevertheless suffered from several important weaknesses. First, the species-centered approach suffers from several issues that affect species distribution modeling in general; specifically, the apparent absence of a species at a particular site may have little to do with site-level conditions, but could be influenced by imperfect detection (MacKenzie et al. 2002) or demographic stochasticity (Tyre et al. 2001). Currently, more complex fitting algorithms used in SDMs do not allow incorporation of imperfect detection, although, work is underway in this area (Kery 2011). Demographic stochasticity effects will always decrease the predictive success of SDMs, but are more likely to cause error rather than bias in testing for landscape effects.

Second, species-centered efforts have not explicitly incorporated important biotic processes such as predation, competition, and facilitation that are often critical drivers of landscape effects (Lima and Zollner 1996). In current SDM approaches, such interactions are implicit in distribution models; vegetation structure is considered to be a proxy for important biotic factors such as predation, competition, and facilitation. However, if co-occurrence data exist, it would be relatively easy to incorporate data on known locations of interacting species directly into SDMs (Box 1; Ovaskainen and Soininen 2011, Zarnetske et al. 2012). Species-centered landscape mapping could integrate both abiotic (e.g. climate, geology) and biotic elements (e.g. distribution of vegetation, species interactions) and would therefore be more likely to represent the realized niche.

Third, such efforts, including the examples above, have tended to rely on dichotomous definitions of habitat and non-habitat ('matrix') (Betts et al. 2006, Lu et al. 2012). While such cover definitions have a statistical basis, in some contexts (particularly for less specialized species in landscapes characterized by gradients) standard metrics that rely on a dichotomous landscape description, such as mean patch size, lose relevancy. 'Habitat' represents a continuum in quality (reflected in reproduction and survival rates) associated with a particular location in the landscape. Similarly, 'matrix' affects animal movement in a way that is not binary (e.g. barrier/non-barrier) (Fig. 2C, F). Indeed, previous weak empirical support for patch size and isolation effects could be due to the fact that many habitat/matrix dichotomies are an inadequate abstraction (Driscoll et al. 2013). However, SDM approaches do not 
necessarily require such a dichotomous habitat/matrix description of the landscape. Fitted values (i.e. predictions) in SDMs are typically continuous, usually representing probability of occurrence. Thus, the spatial pattern of a landscape can be quantified without necessarily requiring hard habitat boundaries. For instance, the rate at which habitat quality changes across space (i.e. the slope of $\hat{p}$ ) could be quantified to depict the steepness of gradients in habitat distributions. A variety of approaches is available for quantifying three-dimensional surfaces, including surface metrology, fractal analysis, and spectral and wavelet analysis (McGarigal and Cushman 2005).

Reflecting biologically-meaningful gradients in speciescentered landscape metrics is likely to be a fruitful avenue for future research. There is also strong precedence for quantifying matrix resistance from a species-centered perspective; both animal movement (Compton et al. 2007), and genetic data (Epps et al. 2007) have been used to parameterize models of functional connectivity for a variety of organisms. The combined use of SDMs defining 'habitat' at landscape scales and quantitative estimates of functional resistance (and isolation) therefore shows promise for testing for congruency between theory and empirical data, even (or especially) in landscapes containing fuzzy boundaries.

A fourth weakness of existing species-centered approaches is that most efforts have not adequately addressed the issue of scale. The most realistic implementation of a species-centered approach requires the recognition that different species perceive landscape pattern across vastly different spatial grains and extents (Wiens 1989). This is because living organisms differ in traits, but also because they vary enormously in size (10-6-100 m; Chave 2013). In this respect, the absence of generalizations about fragmentation effects on populations could be at least partially attributable to mismatches between the scales considered in investigations and the scales perceived and responded to by species of interest.

It may initially seem counterintuitive that generality is most likely to be achieved via measuring habitat patchiness and spatial scale for many individual species. However, without doing this, the immense variety of scales and spatial distributions that exist across taxa is likely to obscure any fundamental ecological signals that actually exist. A key question still to be addressed in landscape ecology is therefore: once we have adjusted for different spatial scales of perception, and differing physical distributions of habitat, will generalities start to emerge? Although finding similarities in response to landscape structure between beetles and elephants may be farfetched (Wiens et al. 1997), without a species-centered approach, this hypothesis will remain untested. An alternative possibility is that even after adjusting for differences in habitat distributions and scales, substantial differences will remain in species' responses to habitat loss and fragmentation. This outcome would be no less interesting, however; new hypotheses can be addressed such as whether species' responses are phylogenetically conserved, determined by life-history traits such as longevity and reproductive output, or whether they depend on biotic elements of the landscape such as predator and/or conspecific abundance.

\section{Conclusion}

Species-centered approaches are not the only legitimate means for measuring landscapes. Different simplifications will be suitable for various purposes, and often a combination of approaches can be particularly useful. While it is important to acknowledge the risk of missing key habitat loss and fragmentation effects by adopting human-defined conceptions of landscapes (Cushman et al. 2008, Fig. 2), human-defined cover types are most frequently used as conservation and policy objectives. Using such cover types as measures of landscape composition and configuration may often be more readily integrated into policy; after all, it is primarily human-defined land-cover categories (e.g. old growth, native prairie, mangrove forest) that are used in management. The ecology of anthropogenically modified landscapes can perhaps best be understood by simultaneously considering species-centered approaches and approaches focusing on changes in landscape pattern that are directly relevant to humans. The degree to which species-specific habitat distributions correspond to humandefined cover types or anthropogenic disturbances can also be calculated post-hoc to facilitate interpretation of species-centered results by managers (e.g. Table 2).

Nevertheless, we hypothesize that cross-species generalities in responses to habitat loss and fragmentation are essentially untestable unless landscape mosaics are defined using models that reflect differing species-specific habitat relations. The emergence of generalities will not only enhance scientific understanding of biotic processes driving fragmentation effects, but will also allow managers and policy makers to better predict species' sensitivities to landscape change based on knowledge about the spatial distribution of patches and species' life-history traits.

As the field of landscape ecology continues to grow, there is some risk that it will dissolve into different subdisciplines that continue to collect regionally specific facts that are not connected by underlying theory or consistent definitions. We hope that broader application of speciescentered approaches will provide an initial step toward uniting the field in search of greater generality.

Acknowledgements - We thank R. Fletcher, and R. Didham for reviews that improved earlier versions of this manuscript. We also thank J. Alexander for access to bird distribution data. Z. Yang assisted with the processing of remotely sensed data. This study was supported by US National Science Foundation grants (NSF-ARC-0941748 and DEB-1050954) to MGB.

\section{References}

Altman, B. and Stephens, J. L. 2012. Land managers guide to bird habitat and populations in oak ecosystems of the Pacific Northwest. - American Bird Conservancy and Klamath Bird Observatory.

Andrén, H. 1994. Effects of habitat fragmentation on birds and mammals in landscapes with different proportions of suitable habiat - a review. - Oikos 71: 355-366.

Balmford, A. et al. 2003. Measuring the changing state of nature. - Trends Ecol. Evol. 18: 326-330.

Barnosky, A. D. et al. 2012. Approaching a state shift in Earth's biosphere. - Nature 486: 52-58. 
Belisle, M. 2005. Measuring landscape connectivity: the challenge of behavioral landscape ecology. - Ecology 86: 1988-1995.

Betts, M. G. et al. 2006. The importance of spatial autocorrelation, extent and resolution in predicting forest bird occurrence. - Ecol. Model. 191: 197-224.

Betts, M. G. et al. 2007. Thresholds in songbird occurrence in relation to landscape structure. - Conserv. Biol. 21: $1046-1058$

Bowman, J. 2003. Is dispersal distance of birds proportional to territory size? - Can. J. Zool. 81: 195-202.

Chave, J. 2013. The problem of pattern and scale in ecology: what have we learned in 20 years? - Ecol. Lett. 16: 4-16.

Compton, B. W. et al. 2007. A resistant-kernel model of connectivity for amphibians that breed in vernal pools. - Conserv. Biol. 21: 788-799.

Connor, E. F. et al. 2000. Individuals-area relationships: the relationship between animal population density and area. - Ecology 81: 734-748.

Cushman, S. A. et al. 2008. Do forest community types provide a sufficient basis to evaluate biological diversity? - Front. Ecol. Environ. 6: 13-17.

Devictor, V. et al. 2008. Distribution of specialist and generalist species along spatial gradients of habitat disturbance and fragmentation. - Oikos 117: 507-514.

Didham, R. K. et al. 2012. Rethinking the conceptual foundations of habitat fragmentation research. - Oikos 121: 161-170.

Drapeau, P. et al. 2000. Landscape-scale disturbances and changes in bird communities of boreal mixed-wood forests. - Ecol. Monogr. 70: 423-444.

Driscoll, D. A. et al. 2013. Conceptual domain of the matrix in fragmented landscapes. - Trends Ecol. Evol. 28: 605-613.

Elith, J. et al. 2006. Novel methods improve prediction of species' distributions from occurrence data. - Ecography 29: 129-151.

Elith, J. et al. 2008. A working guide to boosted regression trees. - J. Anim. Ecol. 77: 802-813.

Epps, C. W. et al. 2007. Optimizing dispersal and corridor models using landscape genetics. - J. Appl. Ecol. 44: 714-724.

Ewers, R. M. et al. 2010. Making statistics biologically relevant in fragmented landscapes. - Trends Ecol. Evol. 25: 699-704.

Fahrig, L. 2003. Effects of habitat fragmentation on biodiversity. - Annu. Rev. Ecol. Evol. Syst. 34: 487-515.

Fahrig, L. 2013. Rethinking patch size and isolation effects: the habitat amount hypothesis. - J. Biogeogr. 40: 1649-1663.

Fahrig, L. et al. 2011. Functional landscape heterogeneity and animal biodiversity in agricultural landscapes. - Ecol. Lett. 14: 101-112.

Fischer, J. and Lindenmayer, D. B. 2007. Landscape modification and habitat fragmentation: a synthesis. - Global Ecol. Biogeogr. 16: 265-280.

Fischer, J. et al. 2005. Lizard distribution patterns in the Tumut Fragmentation "Natural Experiment" in south-eastern Australia. - Biol. Conserv. 123: 301-315.

Gillies, C. S. and Clair, C. C. S. 2008. Riparian corridors enhance movement of a forest specialist bird in fragmented tropical forest. - Proc. Natl Acad. Sci. USA 105: 19774-19779.

Guisan, A. and Zimmermann, N. E. 2000. Predictive habitat distribution models in ecology. - Ecol. Model. 135: 147-186.

Haila, Y. 2002. A conceptual genealogy of fragmentation research: from island biogeography to landscape ecology. - Ecol. Appl. 12: 321-334.

Haila, Y. et al. 1983. Colonization of islands by land birds - prevalence functions in a Finnish archipelago. - J. Biogeogr. 10: 499-531.
Halstead, K. E. 2013. A 'Bird's Eye View': using a species-centered approach to investigate drivers and patterns of avian species richness in oak systems of the Rogue Basin, Oregon. - MS thesis, Oregon State Univ., Corvallis.

Hanski, I. 1998. Metapopulation dynamics. - Nature 396: 41-49.

Hanski, I. A. 2011. Eco-evolutionary spatial dynamics in the Glanville fritillary butterfly. - Proc. Natl Acad. Sci. USA 108: 14397-14404.

Holland, J. D. et al. 2005. Body size affects the spatial scale of habitat-beetle interactions. - Oikos 110: 101-108.

Kery, M. 2011. Towards the modelling of true species distributions. - J. Biogeogr. 38: 617-618.

Leibold, M. A. et al. 2004. The metacommunity concept: a framework for multi-scale community ecology. - Ecol. Lett. 7: 601-613.

Lima, S. L. and Zollner, P. A. 1996. Towards a behavioral ecology of ecological landscapes. - Trends Ecol. Evol. 11: 131-135.

Lindenmayer, D. B. et al. 1995. A method for predicting the spatial distribution of arboreal marsupials. - Wildl. Res. 22: 445-456.

$\mathrm{Lu}, \mathrm{N}$. et al. 2012. Species-specific habitat fragmentation assessment, considering the ecological niche requirements and dispersal capability. - Biol. Conserv. 152: 102-109.

MacArthur, R. H. and MacArthur, J. W. 1961. On bird species diversity. - Ecology 42: 594-598.

MacArthur, R. H. and Wilson, E. O. 1967. The theory of island biogeography. - Princeton Univ. Press.

MacKenzie, D. I. et al. 2002. Estimating site occupancy rates when detection probabilities are less than one. - Ecology 83: $2248-2255$.

Manning, A. D. et al. 2004. Continua and Umwelt: novel perspectives on viewing landscapes. - Oikos 104: 621-628.

McGarigal, K. and Cushman, S. A. 2005. The gradient concept of landscape structure. - In: Wiens, J. A. and Moss, M. (eds), Issues and perspectives in landscape ecology. Cambridge Univ. Press, pp. 112-119.

McIntyre, S. and Barrett, G. W. 1992. Habitat variegation, an alternative to fragmentation. - Conserv. Biol. 6: 146-147.

Ovaskainen, O. and Soininen, J. 2011. Making more out of sparse data: hierarchical modeling of species communities. - Ecology 92: 289-295.

Pearson, S. F. 1997. Hermit warbler (Setophaga occidentalis). - In: Pool, A. (ed.), The birds of North America online. Cornell Lab of Ornithology, <http://bna.birds.cornell.edu/bna/species/ $303>$.

Prugh, L. R. et al. 2008. Effect of habitat area and isolation on fragmented animal populations. - Proc. Natl Acad. Sci. USA 105: 20770-20775.

Ralph, C. J. et al. 1995. Monitoring bird populations by point counts. - Pacific Southwest Research Station, Albany, CA.

Ries, L. et al. 2004. Ecological responses to habitat edges: mechanisms, models, and variability explained. - Annu. Rev. Ecol. Evol. Syst. 35: 491-522.

Seavy, N. E. and Alexander, J. D. 2011. Interactive effects of vegetation structure and composition describe bird habitat associations in mixed broadleaf-conifer forest. - J. Wildl. Manage. 75: 344-352.

Shirley, S. et al. 2013. Species distribution modeling for the people: unclassified landsat TM imagery predicts bird distributions at fine resolutions. - Divers. Distrib. 19: 855-866.

Smith, M. J. et al. 2011. Independent effects of connectivity predict homing success by northern flying squirrel in a forest mosaic. - Landscape Ecol. 26: 709-721.

Taylor, P. D. et al. 1993. Connectivity is a vital element of landscape structure. - Oikos 68: 571-573. 
Tischendorf, L. and Fahrig, L. 2000. How should we measure landscape connectivity? - Landscape Ecol. 15: 633-641.

Tyre, A. J. et al. 2001. Inferring process from pattern: can territory occupancy provide information about life history parameters? - Ecol. Appl. 11: 1722-1737.

Vance, M. D. et al. 2003. Effect of reproductive rate on minimum habitat requirements of forest-breeding birds. - Ecology 84: 2643-2653.

Watling, J. I. et al. 2011. Meta-analysis reveals the importance of matrix composition for animals in fragmented habitat. - Global Ecol. Biogeogr. 20: 209-217.

Supplementary material (Appendix ECOG-00740 at $<$ www.ecography.org/readers/appendix $>$ ). Appendix 1 .
Wiens, J. A. 1976. Population responses to patchy environments. - Annu. Rev. Ecol. Syst. 7: 81-120.

Wiens, J. A. 1989. Spatial scaling in ecology. - Funct. Ecol. 3: 385-397.

Wiens, J. A. et al. 1997. Patchy landscapes and animal movements: do beetles percolate? - Oikos 78: 257-264.

Zarnetske, P. L. et al. 2012. Biotic multipliers of climate change. - Science 336: 1516-1518.

Zitske, B. P. et al. 2011. Negative effects of habitat loss on survival of migrant warblers in a forest mosaic. - Conserv. Biol 25: 993-1001. 